\title{
Da televisão para o cinema: paródia e memória da ditadura militar brasileira
}

\section{Mônica Almeida Kornis}

Doutora; Escola de Ciências Sociais da Fundação Getulio Vargas monica.kornis@fgv.br

\section{Resumo}

O presente artigo tem a finalidade de examinar como os filmes A taça do mundo é nossa (2003), dirigido por Lula Buarque de Hollanda e Reis e ratos (2012), dirigido por Mauro Lima representaram a história da ditadura militar brasileira. Com base na discussão sobre o contexto da transmediação no cinema e na televisão, pretende-se analisar como a construção de uma memória sobre esse período, em ambos os filmes produzidos pela Globo Filmes, se pautou em paródias baseadas nos bemsucedidos formatos televisivos criados na Rede Globo ao longo dos anos 1980 por Guel Arraes e pelo grupo Casseta \& Planeta. No cinema, essas produções perderam certamente a dimensão inovadora contida, décadas antes, em seriados televisivos. Ao mesmo tempo, construíram uma memória que coloca aquele período como algo acabado no passado, longe de tensões do momento em que os filmes foram produzidos.

\section{Palavras-chave}

Televisão. Cinema. Ditadura militar brasileira. Rede Globo. Globo Filmes.

\section{Cinema, televisão e ditadura militar brasi- leira}

Narrativas cinematográficas e televisivas sobre a ditadura militar brasileira integram o cenário da nossa produção audiovisual já há algumas décadas. 0 cinema tematizou questões ligadas àquele contexto histórico desde seus primeiros momentos, como foram os casos dos filmes $O$ desafio (lançado em 1965), de Paulo César Sarraceni, Terra em transe (de 1967), de Glauber Rocha, e A opinião pública (1967), de Arnaldo Jabor, se nos detivermos apenas nesses três grandes títulos da produção nacional. Foram ao todo mais de uma cente- 
na de documentários e de filmes ficcionais produzidos sobre o tema até hoje, entre uma produção de mercado com um tratamento naturalista da questão, e uma outra vertente mais instigante e inovadora do ponto de vista narrativo e estético como Blá-blá-blá (1968), de Andrea Tonacci, Iracema uma transa amazônica (1974), de Jorge Bodansky e Orlando Sena e Cabra marcado para morrer (1984), de Eduardo Coutinho, entre outros, se nos concentrarmos em produções realizadas ainda durante o governo militar.

Na televisão, em particular na Rede Globo, na primeira metade da década de 1970, o tratamento alegórico em algumas telenovelas do teatrólogo Dias Gomes e algumas situações vividas por personagens do seriado A grande família, escrito por teatrólogos igualmente ligados ao Partido Comunista como Oduvaldo Viana Filho e Armando Costa, assim como as experiências documentais realizadas no programa Globo Repórter, remetiam-se criticamente àquele contexto (MARTINS, 2011; SACRAMENTO, 2011; 2012). Foi, no entanto, a partir da segunda metade dos anos 1980, no início do processo de redemocratização, que as referências na televisão se tornariam um pouco mais explícitas, mesmo que ainda tímidas, tal como ocorreu no epílogo da minissérie Anos Dourados e na telenovela Mandala, ambas exibidas em 1986, assim como, um ano antes, no seriado Armação Ilimitada. Com o foco na trajetória de jovens ao longo dos anos 1960 e 1970, foi a minissérie Anos Rebeldes (1992) que reconstruiu o período em suas tensões familiares, amorosas e políticas, bem ao estilo de uma narrativa clássica, melodramática sem dúvida, mas com soluções singulares na sua estrutura e em seu desfecho (KORNIS, 2001; 2011).

Se a vocação televisiva para o tratamento da história já fora evidenciada desde os anos 1970, sobretudo em telenovelas oriundas da adaptação de clássicos da literatura brasileira, a Rede Globo contemplara nos anos 1980 a história recente do país, e mais especificamente o período da ditadura militar, momento no qual ela própria se fortalecera como a maior empresa de comunicação do país. A incorporação em sua produção ficcional de fatos e momentos da história brasileira se impôs com maior força ainda na primeira metade da década de 1980 com a criação de um novo formato televisivo - as minisséries das chamadas "séries brasileiras" -, aprofundando o lugar da Rede Globo como importante agente na construção de uma identidade nacional (KORNIS, 2007). Com características melodramáticas e em consonância com os gêneros frequentados pelo cinema de mercado, a programação ficcional seguia modelos já experimentados por narrativas voltadas para o grande público. Com o passar do tempo, a televisão consolidou formatos e investiu na diversificação de sua produção ficcional, o que ampliou as possibilidades de tratamentos mais inovadores, mesmo sem 
romper com o objetivo de atingir um grande público numa programação de entretenimento e que veio igualmente a contemplar a narrativa em tempos passados. Ao passar a produzir ou coproduzir filmes com a criação da Globo Filmes no final dos anos 1990 (BUTCHER, 2006), a empresa passou a exportar para o cinema formatos diversos experimentados na televisão, em particular dedicados ao humor tanto em comédias com seu star system de telenovelas e minisséries, quanto em seriados e minisséries cujos diretores e atores que vinham experimentando com sucesso novos padrões estilísticos desde a segunda metade dos anos 1980, naquilo que mais tarde seria identificado como a produção do Núcleo Guel Arraes. A temática "passado histórico" encontraria igualmente lugar nessa produção que lançava a empresa no mercado audiovisual, e lhe permitia reafirmar um lugar importante como produtora de "conteúdo nacional".

O objetivo do presente texto é examinar como, nesse processo identificado em estudos recentes como de transmediação, se realizou a reconstrução histórica do período da ditadura militar, especificamente em produções cinematográficas concebidas a partir de ficções televisivas e seriados humorísticos da Rede Globo que se consolidaram com sucesso e de forma inovadora a partir da segunda metade da década de 1980. Nesse sentido, examinaremos os filmes A taça do mundo é nossa (de 2003) e Reis e ratos (de 2012) por se adequarem a essas características, ao contrário de outros filmes produzidos também pela Globo Filmes, mas que não se aproximam de formatos criados pela própria televisão, tais como Zuzu Angel (2006), de Sergio Resende, $A$ dona da história (2004) de Daniel Filho e o $O$ ano em que meus pais saíram de férias (2006), de Cao Hamburger, além do documentário Simonal - ninguém sabe o duro que dei (2009), de Claudio Manoel, Micael Langer e Cavito Leal, todos igualmente produzidos pela Globo Filmes. Interessa-nos assim, pensar no trânsito para o cinema das experiências que nascem na própria Rede Globo, com forte aporte financeiro da nova empresa do grupo, a Globo Filmes, que se dirigem pela via do humor à reconstrução do passado.

\section{Anos 1980: minisséries e novos seriados humorísticos}

Retornar ao tema da diversidade da programação televisiva da Rede Globo ocorrida nos anos 1980 é fundamental para o entendimento das transformações havidas ao longo desta década na produção da emissora, e que marcará a realização dos dois filmes em questão, já nos anos 2000. Muito bem-sucedidos quando criados, esses novos produtos - entre seriados humorísticos e minisséries - impulsionariam uma produção cinematográfica ala- 
vancada alguns anos depois pela Globo Filmes, em parcerias diversas, de produtoras independentes a distribuidoras internacionais. Para ilustrar esse momento inicial, vale lembrar que a minissérie $O$ Auto da Compadecida exibida no início de 1999 transformou-se em filme ao final do mesmo ano, e foi o primeiro produto a migrar do formato televisivo para o cinema. Em seguida A invenção do Brasil (2000), já com o foco na história do país - e de alguma maneira aprofundando o "conteúdo nacional" defendido pela emissora - foi exibida naquele ano como minissérie, e sua transposição para o cinema ocorreu no ano seguinte em Caramuru - a invenção do Brasil. Ambas as experiências foram conduzidas pelo diretor Guel Arraes (no segundo caso em parceria com o cineasta Jorge Furtado), cuja trajetória na Rede Globo e posteriormente em produções cinematográficas da Globo Filmes é importante para nossa análise.

A origem dessa produção televisiva inovadora, de natureza humorística, se deu no início da redemocratização do país, isto é, a partir do ano de 1985. Alguns anos antes, já haviam ocorrido algumas mudanças no formato da produção ficcional da emissora, com a implantação do formato de minisséries que, em produções mais refinadas e de menor duração, seguia, contudo, em sua concepção mais geral a tradição narrativa das telenovelas.

Foi no formato de seriado e também da programação humorística que inovações fundamentais ocorreram, não só do ponto de vista temático, mas sobretudo da própria linguagem televisiva. Esse processo será aqui brevemente traçado a partir do exame da trajetória de seus diretores, roteiristas e atores, considerando que é fundamental perceber a origem de uma nova geração que ingressava na televisão naquele momento, com um passado recente experimentado em grupos alternativos de teatro, na chamada imprensa nanica, reunidos na televisão na maior parte dos casos sob a direção de Guel Arraes. Por outro lado, o diretor de criação da Rede Globo naquele momento, Daniel Filho, reafirmava seu lugar decisivo na emissora, o que havia se inaugurado no ano de 1969 quando assumiu a direção de teledramaturgia da emissora tendo ao seu lado Janete Clair, o que significara a adoção de um novo padrão de telenovela, com temática nacional e tratamento realista. A sua forte presença na empresa pode ser ainda constatada por ter sido ele o criador, mais adiante, da própria Globo Filmes, responsável pela abertura de novas frentes para a produção ficcional daquele grupo empresarial.

O primeiro novo produto foi Armação Ilimitada, exibido uma vez por mês entre 1985 e 1988. Seu diretor geral, o pernambucano Guel Arraes, havia ingressado na Rede Globo no início daquela década, ao retornar do exterior, com passagens por países africanos e pela 
França, onde se interessara por cinema e desenvolvera algumas experiências em Super-8. Seus primeiros trabalhos na emissora foram em telenovelas, em conjunto com Silvio Abreu e Jorge Fernando, cujo trabalho era explicitamente marcado pelo viés do humor, experiência até então inédita para Guel. Este diretor declarou, em depoimento transcrito no livro Guel Arraes: um inventor no audiovisual brasileiro, organizado por Alexandre Figueroa e Yvana Fechine (2008) que foi a partir da televisão e mais especificamente a partir da telenovela Jogo da vida (1981-82), que ele passaria a conhecer as chanchadas, uma marca inspiradora do trabalho daqueles diretores. Se a chanchada era explicitamente citada como referência, a paródia era igualmente presente. Foi nessa tendência que o seriado Armação Ilimitada abordava situações tipicamente cariocas, intercaladas por aventuras amorosas e esportivas, numa edição rápida até então desconhecida em programas televisivos. Nascia ali um novo tratamento narrativo e estético centrado no humor que se aprofundaria em novos projetos ao longo das décadas seguintes. Uma das protagonistas do seriado, Andrea Beltrão, atuava como filha de um ex-exilado político, com a experiência herdada do grupo teatral Asdrúbal Trouxe o Trombone, que primava pelo aspecto lúdico, humor irreverente e pela crítica comportamental. Marco da cena teatral carioca dos primeiros anos da década de 1970, o grupo Asdrúbal Trouxe o Trombone era integrado por nomes que se projetariam a partir da década seguinte na emissora, tais como Regina Casé, Luis Fernando Guimarães, Patrícia Travassos (também roteirista de Armação Ilimitada) e Pedro Cardoso, dentre outros. 0 seriado diferia assim não só do humor dos tradicionais programas do gênero, mas também de outros seriados, mesmo que inovadores em sua temática, como por exemplo havia sido o caso de Malu Mulher, exibido no final dos anos 1970, voltado para a discussão de questões comportamentais contemporâneas. Arlindo Machado (2000) destaca as inúmeras possibilidades estilísticas do estilo narrativo de Armação Ilimitada, apontando para a alternância na condução de narrativas como a de um programa de rádio, de chanchada, de programas de auditório e de paródias de seriados americanos, além da absorção de elementos formais de variados produtos televisivos e da citação de programas da própria Rede Globo. Alexandre Figueroa e Yvana Fechine $(2008 ; 2010)$ apontam, por sua vez, para o ritmo acelerado responsável pela associação de um conjunto de informações - verbais, sonoras e visuais - nessa e em outras produções de Arraes marcadas pela paródia.

Outras duas experiências humorísticas inovadoras foram produzidas nos últimos anos da década de 1980, já igualmente trabalhada por Yvana Fechine (2008), em artigo no livro organizado juntamente com Alexandre Figueroa: TV Pirata (1988-1990), também dirigido 
por Guel Arraes, e em seguida os esquetes do Casseta e Planeta, que passaria em 1992 a ter um programa próprio intitulado Casseta \& Planeta Urgente!, e seis anos mais tarde seria integrado ao Núcleo Guel Arraes da emissora. Se o seriado Armação Ilimitada incorporou atores e atrizes do teatro alternativo nascido nos anos 1970 no Rio de Janeiro, esses dois programas trouxeram jovens redatores da imprensa alternativa com tradição de crítica ao regime militar e com uma experiência de humor irreverente já desde aquela mesma década. Houve um encontro da experiência de Claudio Paiva (que já trabalhara na Globo desde 1987 como roteirista), Reinaldo e Hubert - que haviam sido redatores de $O$ Pasquim nos anos 1970, e que em 1984 criaram o tabloide de humor Planeta Diário - com um grupo egresso da militância no movimento estudantil e no clandestino Partido Comunista Brasileiro que criou em 1978 a satírica publicação Casseta Popular, vendido nas praias, nos bares e nas universidades cariocas. Foram eles Beto Silva, Helio de La Peña e Marcelo Madureira, seguidos por Claudio Manoel e Bussunda.

As inovações formais advindas de toda essa programação que acabaria tendo à frente Guel Arraes, mesmo antes de o próprio ser responsável por um núcleo de produção ficcional, o que ocorreu em 1991, marcou definitivamente a programação da Rede Globo, que passou a contar com uma série de parcerias com produtoras independentes como a paulista 02 e a carioca Conspiração Filmes nos anos seguintes. Essa experiência que, nas palavras de Yvana Fechne (2008) em seu texto em publicação organizada juntamente com Alexandre Figueroa e já acima mencionado, foi um tanto original e criativa quanto bem-sucedida comercialmente desde os seus primórdios, nos anos 1980, conviveu assim com o momento em que a criação da Globo Filmes passava a produzir para o cinema, utilizando-se de modelos experimentados com sucesso na televisão, entre outras tendências mais convencionais dirigidas preferencialmente a comédias com atores consagrados da emissora. Se alguns títulos obtiveram grande sucesso, tal não foi o caso nos dois filmes que a seguir serão analisados, $A$ taça do mundo é nossa e Reis e Ratos.

\section{A ditadura militar brasileira no cinema via formato televisivo}

O formato televisivo do programa Casseta e Planeta e o estilo do Núcleo Guel Arraes compuseram as narrativas dos filmes mencionados, num momento em que ambos já se encontravam bastante arraigados na programação da Rede Globo, e que já haviam se desdobrado em inúmeros programas inspirados nas produções do Núcleo Guel Arraes. A reconstrução histórica do período da ditadura militar no caso de $A$ taça do mundo é nossa, e do pe- 
ríodo pré-golpe em Reis e Ratos consolidaram a tradição do humor, em paródias e sátiras do cotidiano. No primeiro filme, há um acento na identificação com fatos da história política do ano de 1970, e em particular com a vitória do Brasil na Copa do Mundo daquele ano. As tradicionais referências ao país se encontram explicitadas na narrativa que, nesse sentido, se apoia num tratamento mais realista de questões nacionais via futebol e pela música-hino da Copa de 1970, Prá Frente, Brasil, de Miguel Gustavo, assim como pelos letreiros com as cores da bandeira, o que se aproximaria de uma tendência já explicitada na programação ficcional da emissora em minisséries e também em telenovelas na linha da verossimilhança. Opera ainda com personagens bastante caricaturais: general burro, mulher arrivista e autoritária, militante de esquerda dogmático, mas superprotegido pela mãe, hippie, e cantor pop sem talento que quer fazer sucesso. No segundo caso, mais afeito ao formato dos seriados do referido Núcleo, há um excesso de voz off, citações de cinema, sendo as referências históricas mais longínquas sob uma narrativa anti-naturalista. A paródia a filmes americanos é recorrente em ambos os filmes, sendo que o segundo é ainda evidenciado pelos os trejeitos de grande parte do elenco, e pela sonoridade de vozes dubladas nas falas dos dois personagens em conflito.

Em comum, o espírito de aventura move o conflito em ambos os filmes, com citações do gênero policial. Percebe-se que a marcação cronológica é bastante definida (1963-1964 e 1970), e expressa momentos de radicalização dos conflitos políticos no país: em $A$ taça do mundo é nossa, a presença dos militares a partir de 1964 leva a um acirramento das tensões entre esse segmento no poder e "terroristas subversivos" em meio aos festejos pela conquista do Brasil do título de tricampeão do mundo (e por que não ao momento mais repressivo do período, o governo do presidente Emílio Garrastazu Médici), enquanto o acirramento das tensões que antecedem o golpe militar se deslocam para a presença de forças antagônicas internacionais que atuam em conflito no país. Da mesma forma que em A taça do mundo é nossa, há um jogo de imagens que alterna preto e branco e cor, sendo que nesse caso com o objetivo de simular filme antigo, enquanto o filme do Casseta \& Planeta se utiliza do preto e branco na simulação de cinejornal.

Dirigido por Lula Buarque de Hollanda, um dos sócios da produtora independente Conspiração Filmes, responsável pela co-produção do filme com a Globo Filmes, $A$ taça do mundo é nossa estreou em 2003, tendo sido escrito e protagonizado pelos integrantes do programa Casseta \& Planeta - Urgente!. Se na televisão o programa era marcado por esquetes humorísticos, no cinema, ao contrário, o filme narra as peripécias de um grupo composto 
por um militante de esquerda, um hippie e um cantor pop frustrado que passam a ser considerados terroristas e que, perseguidos, acabam roubando a Taça Jules Rimet, conquistada pelo Brasil na Copa do Mundo de 1970. 0 diretor se remete à tradição do cinema popular brasileiro na vertente da chanchada, e a dimensão de sátira se faz presente na configuração caricatural de todos os personagens, mesmo que em conflito.

A apresentação do filme anuncia o tempo histórico da ação e o conflito já está anunciado em tom de sátira. Nas cenas iniciais, com um tratamento caricatural, há um conjunto de referências a tensões políticas da época. É apresentado um certificado de censura no qual somente o título do filme é real: o tom irônico perpassa todo o texto com data de assinatura em abril de 1970 e validade até março de 1974 (ou seja, aprovado para apresentação e validade durante o governo Médici) e com uma série de alusões à virilidade masculina: o justificado de censura qualifica o filme como "cenas de impotência explícita", o diretor da censura com o nome H. Romeu Pinto e "proibição para menores de dezoito centímetros". Segue-se o texto de abertura do filme que já evidencia a tensão, mesmo que no registro da sátira:

Uma ditadura militar estava no poder. Os militares só pensavam em poder. Poder com os estudantes, poder com os trabalhadores, poder com a imprensa. Naquele tempo, era poda. Em 1970, o Brasil também se sagrou tricampeão mundial de futebol na Copa do México... Esse filme tem a ver com essas paradas aí... (CASSETA \& PLANETA, 2003).

Com a simulação de imagens de cinejornais de época, em preto e branco e com tratamento cômico, há uma explosão durante feira agropecuária no Rio Grande do Sul na qual estão presentes militares, cujo efeito maior é a morte de uma das vacas do concurso, a predileta do Presidente da República. Instaurada a suspeita de atentado terrorista. A seguir, imagens que fazem uma paródia com as tomadas de jogos de futebol do Canal 100, numa partida assistida por poucos militares e de disputa de dois times no estádio do Maracanã: Forças Armadas x "uma seleção de perigosos comunistas subversivos". Definem-se os dois eixos do conflito: militares e uma oposição perigosa também designada como terrorista. Há uma locução em off de que esta disputa teve início no ano de 1964, clara referência ao ano do golpe militar. O gol das Forças Armadas é um tiro, há um corre-corre com situações que apontam para a derrota do adversário ao grupo dos "milicos", com um placar de 25 a 0 para os "representantes das Forças Armadas", com os adversários dizimados em campo. Seguem-se imagens de época de passeatas, com estudantes sendo atacados por policiais, com a seguinte locução: "[...] sem a presença de autoridades civis, militares e eclesiásticas, foi realizada no Rio de Janeiro uma manifestação de baderneiros que querem, a qualquer custo, impingir 
suas ideologias exóticas estranhas à nossa sociedade [...]" (CASSETA \& PLANETA, 2003). A seguir, o personagem Wladimir (Lênin ou Palmeira, instaura-se uma dúvida), interpretado por Bussunda, picha o muro com erros de português, para, em seguida, já com imagens a cores, escrever "abaixo a ditadura", no mesmo momento em que vê general fraco com esposa feia e filha atraente entrarem na churrascaria "Chuletão Gaúcho" para assistir à final da Copa do Mundo. Na churrascaria, em meio a uma série de peripécias na mesa do general Mirandinha, desenvolve-se a aventura entre três supostos terroristas atabalhoados - o comunista Wladimir (sempre sectário, e paparicado por sua mãe, o ator Reinaldo), o hippie Denilson e o cantor pop Peixoto Carlos - a partir da explosão no local. Há uma caracterização bastante cômica dos trajes e linguajar desses três personagens (Bussunda, Helio De la Penã e Hubert) da mesma forma que em relação ao fraco general Mirandinha (Claudio Manoel), sua esposa autoritária Dolores (Marcelo Madureira) e a filha sexy Lucy Ellen (Maria Paula), que mais adiante se aproximará do trio.

As referências ao momento histórico não se concentram cronologicamente nas cenas: há um vietnamita que passa na cena, um encapuzado (embaixador) conduzido por militante no meio da rua em alusão ao sequestro de embaixadores na época, Che Guevara no meio da mata, por exemplo. Os trajes, mesmo que caricaturais, buscam verossimilhança, assim como o linguajar e a menção a uma dicotomia entre militares e "terroristas" (como em vários filmes para o grande público a oposição entre regime e luta armada desenvolve a ação dramática da narrativa). Da mesma forma, as músicas evocam o contexto, de Prá Frente Brasil a Guantanamera, passando por canções de Roberto Carlos e Tim Maia. Essas observações se orientam para a hipótese de que o filme se filia a uma tradição televisiva de construção de uma identidade de nação, mesmo com uma dimensão de paródia, de escracho por vezes, fiel ao humor preconizado pelo programa Casseta \& Planeta Urgente! certo, mas também, mesmo que com singularidades, a minisséries e telenovelas de viés realista, seguindo a tradição da teledramaturgia da emissora desde 1969. A questão da verossimilhança conta ainda com a presença dos jogadores da Copa de 1970, Carlos Alberto Torres e Jairzinho, no momento em que o carro que os leva pelas ruas, juntamente com a Taça Jules Rimet, é sequestrado pelo trio terrorista, que passa a ser dono da taça que premiou a seleção brasileira no México.

Há duas sequências cuja sátira dirige-se exclusivamente aos militares. Numa casa noturna que estampa em néon a frase "a longa noite da ditadura", realiza-se festa para os militares, de soldados à oficialidade. Juntos, ao final de uma série de quadros de humor, dançam - em coreografia de discoteca, sob a batuta de um general, também cantor pop com cabelo 
blackpower - ao som da música "Que beleza", de Tim Maia, aqui intitulada "Que dureza". A segunda sequência trata de uma reunião do Serviço Nacional de Informações (SNI), que se reduz a um quiosque numa festa com essa designação. As estratégias de ação do grupo ali reunido se constroem por peças de brinquedo com soldadinhos de chumbo, tanques e aviões de caça, como uma maquete de cenário de guerra, como que uma diversão de jogo infantil. Os tratamentos satíricos no campo oposto se concentram em sequências de Wladimir com a supermãe e também nas peripécias de seu namoro com Lucy Ellen, sem a mesma contundência do deboche dirigido aos militares.

As sequências finais do filme, após o sequestro do avião cujo destino era o "Amazonas" para fazer guerrilha, numa referência à opção armada de revolução no campo, trazem novos elementos na linha da paródia. General Mirandinha também segue para lá para pegálos, estimulado pela esposa Dolores. Acaba sendo jogado pela janela do avião, o que permite a Dolores passar a namorar o general linha dura denominado Manso, que também estava no avião. Enquanto os sequestradores estão perdidos na floresta, Wladimir encontra Che Guevara (Claudio Manoel) que, por paquerar Lucy Ellen, é morto por Wladimir. É Lucy Ellen que encontra a taça no meio do mato, iniciando uma disputa entre militares e "terroristas" pela taça, até que alguns começam a afundar em terreno de areia movediça. Chegam os norte-americanos, que matam todos, numa paródia aos filmes de gênero nos quais norteamericanos impõem seu poder ao esmagar o inimigo. 0 filme se revela como filme no momento em que todos os personagens começam a se levantar, conversam que o próprio não pode acabar desta maneira por ser uma comédia, e Maria Paula empurra o letreiro "fim" para extracampo. Há uma busca por um novo desfecho com cenas do grupo "terrorista" juntamente com o general Mirandinha que se apaixonou pela mãe de Wladimir. No retorno para casa, há uma queda do avião. Já cessado o conflito entre militares e "terroristas", saem agora em busca da taça perdida neste acidente. Acabam encontrando uma estatueta que não era a Jules Rimet e sim a do Oscar, o que os leva a comemorar a premiação do filme nos Estados Unidos antes mesmo de ele haver terminado. A sequência que fecha o filme é um debate sobre o próprio entre atores e plateia, uma sátira à própria crítica de cinema, num jogo de perguntas e respostas insignificantes e ríspidas, mas com aparência de seriedade. Alterna-se assim um final de filme norte-americano com comédia e uma ironia à prática da crítica. 0 passado está distante, não há mais tensão. Se na televisão o grupo Casseta \& Planeta se referenciava em seu humor à própria produção televisiva, no cinema a sátira se dirigiu aos fil- 
mes de gênero e também à própria crítica, via debate na cena final. Tratava-se agora de um programa para o cinema, e a estratégia de metalinguagem era a ele dirigida.

Já a reconstrução da conjuntura que antecedeu o golpe de 1964 se realiza em Reis e Ratos (2012). Com distribuição da Warner Brothers Pictures e produção da Globo Filmes juntamente com a produtora independente Natasha Filmes (tendo a frente Paula Lavigne), o filme foi dirigido por Mauro Lima, cuja experiência no cinema havia se iniciado nos anos 1990, após a realização de videoclipes e trabalhos em publicidade. Seu filme mais conhecido foi Meu nome não é Johnny (2008), e a aproximação com Guel Arraes se deu tanto no cinema produzido pela Globo Filmes - Lima foi um dos produtores de Lisbela e o prisioneiro (2003), dirigido por Guel - quanto na televisão, convidado pelo próprio Arraes para dirigir alguns episódios de Ó Pai Ó (2008), no qual ele fora roteirista juntamente com Jorge Furtado. A centralidade da figura de Guel Arraes é decisiva no trânsito entre a produção para a televisão e para o cinema como podemos também aqui perceber, e nesse caso com a incorporação de novos realizadores, e também em novas parcerias do ponto de vista da produção audiovisual. Realizado em pouco mais de duas semanas no ano de 2009, a produção se beneficiou dos cenários da telenovela $O$ bem-amado, construídos no Projac, com atores bastante conhecidos da emissora, como Selton Mello (com vários desempenhos no Núcleo Guel Arraes), Otávio Müller, Cauã Reymond e Rodrigo Santoro, além da marca estilística do Núcleo Guel Arraes.

Nesse filme, as referências históricas são construídas de maneira distinta do filme anterior, mesmo que na linha da paródia. Numa narrativa de comédia policial ambientada durante a Guerra Fria - quando o mundo fora dividido entre duas grandes potências mundiais, Estados Unidos e União Soviética - e cujo conflito se inicia na fictícia cidade de Bacaxá, no Estado do Rio de Janeiro, o filme não pretende identificar na diegese situações e fatos da conjuntura política brasileira pré-golpe de março de 1964, a não ser por dois cortes cronológicos. Não recorre igualmente a um conjunto de símbolos da nacionalidade brasileira esse procedimento se dirige às duas potências, com a exibição de elementos da bandeira norte-americana e da foice e martelo - afastando-se de um tratamento realista mais afeito ao modelo das minisséries históricas.

A história gira em torno das peripécias de um agente da CIA (Selton Mello) que vive no Rio de Janeiro e onde conspira contra o presidente, cujo nome não é mencionado. 0 filme se inicia com teclas de máquina de escrever em movimento, cujo primeiro texto redigido é "The king will come from far away", com voz off feminina que será a narradora de uma história que ela afirma ser suja e que envolve duas nações opositoras, seguida pela inscrição da data 
de 15 de novembro de 1963, acompanhada por alteração na cor da imagem, que passa para preto e branco. Essa alteração de cor realiza a passagem do tempo histórico, que marca um momento de acirramento de tensões - final do ano de 1963 - quando um agente de espionagem norte-americano é incumbido de derrubar o presidente. No campo oposto, há um radialista médium (Cauã Reymond) que incorpora o espírito de um agente da KGB e que, ao receber instruções da URSS, passa a prever o risco que corre o presidente, o que lhe permite interferir nas ações do inimigo. Golpes, chantagens e espionagem se cruzam na narrativa, em clichês típicos do gênero policial, tratados com humor e por mise-en-scène não realista, acrescentada pela presença de voz off em vários momentos da narrativa. Não há uma estratégia de verossimilhança na representação do passado, apesar do recorte histórico já mencionado. Há, no entanto, uma história de amor que se desenvolve de maneira não muito explícita em meio aos conflitos oriundos da Guerra Fria, via os serviços secretos das poderosas agencias de informação, CIA e KGB.

Antes mesmo dos créditos em letras que simulam ser do alfabeto russo e que, invertidas, passam a ser lidas na língua portuguesa e de cenas com um avião sobrevoando o mar, é anunciada uma inauguração na cidade de Bacaxá, Estado do Rio de Janeiro. Segue-se uma explosão de palanque antes mesmo do início da cerimônia e cujo alvo era a cantora de boate e ex-prostituta Amélia Castanho (Rafaela Mandelli) escolhida para participar do evento, e ela própria a narradora do filme. Clima de suspense criado por tratamento sonoro à la filmes de James Bond se soma à música-tema do filme com título homônimo, composta por Caetano Veloso, cujo refrão dialoga com o filme de uma forma bastante reveladora do ponto de vista da atenuação do conflito, ao igualar os homens na condição de reis e ratos, isto é, ao apelar para a dimensão humana de um conflito cuja natureza é fundamentalmente política. Além da referência da narradora do filme, de que se trata de uma história de amor.

As aventuras desse desastrado, mas elegante agente da CIA que simula ser dono de uma sapataria encontram resistência na "oposição" feita pelo radialista médium que "recebe" informações dos soviéticos e que protege, assim, a referida cantora de chantagens por seu passado de prostituta. Há referências históricas muito breves, sempre em contexto de sátira, como a menção à invasão da baia dos porcos pelos norte-americanos, ao assassinato do presidente John Kennedy (Troy afirma ser perigoso viver em um país onde o presidente é baleado), e ao final à revolta dos marinheiros, numa alusão à atuação do Cabo Anselmo no personagem do cantor e compositor Seu Jorge, embebedado pelo inimigo por estar namorando sua mulher. 
O conflito entre as duas forças é constante até o dia do golpe militar, referência em legenda na tela, e que anuncia o desfecho da trama. Sabe-se do fato pelo radialista, que narra que não houve nenhum tiro na revolução que depôs o governo, seguida por imagens de retirada do agente da CIA, e finalmente o encontro em um bar de Hervê e Amélia Castanho, cuja voz em off revela que havia então se iniciado "um tempo de trevas que durou 20 anos", em clara alusão ao período da ditadura militar. Importa, contudo, a ideia de tranquilidade que passa a reinar, com a cena do casal em um bar e ela sozinha diante do mar olhando a partida de um avião, ao som da música de Caetano, cujo refrão "homens são todos iguais, são reis e ratos, são reis ou ratos", celebra o fim do conflito e a vitória do amor. Uma incorreção que é passado, portanto, expurgado como algo longínquo e já terminado.

\section{Considerações finais}

O chamado processo de transmediação que, no caso aqui tratado, se constituiu pela produção de filmes por uma empresa ligada à Rede Globo, propiciou a produção de títulos que incorporaram não só atores televisivos, mas sobretudo formatos nascidos de inovações estilísticas implementadas ao longo da segunda metade da década de 1980 na Rede Globo. A temática "história" e em particular a ditadura militar já frequentara a pequena tela em algumas minisséries e pontualmente em telenovelas, como Mandala e Senhora do Destino. Às minisséries Anos Dourados e Anos Rebeldes, se sucederam Decadência, Hilda Furacão, Caros amigos, Luna Caliente e $J K$ que também se remeteram àquela conjuntura histórica. A diversidade da produção televisiva da emissora a partir dos anos 1980 também nos seriados e a criação da Globo Filmes no final da década seguinte ampliou significativamente a força e a presença do universo dessa grande empresa de comunicação, agora também no cinema.

No caso específico dos filmes aqui tratados, o humor dirigido a produções cinematográficas cujo formato foi originário da própria televisão parece ter se diluído, e chegou ao cinema sem a força inovadora das experiências iniciais televisivas. Por outro lado, assim como a televisão incorporara a temática "história" em seus programas, a Globo Filmes daria prosseguimento à produção de "conteúdo nacional" abrigando a mesma temática, inclusive em títulos com a marca característica do Núcleo Guel Arraes. A reconstrução de histórias no contexto que antecedeu o golpe militar e durante o próprio período da ditadura, centradas no humor e na paródia, não obtiveram o impacto dos formatos que lhes deram origem quando criados na televisão. Vieram ainda a construir uma memória da história do período 
como algo sem impasses, e com desfechos que acenavam para um momento presente distanciado e livre das tensões do passado.

\section{Referências}

BUTCHER, Pedro. A dona da história: origens da Globo Filmes e seu impacto no audiovisual brasileiro. 2006. Dissertação (Mestrado em Comunicação e Cultura) - Programa de PósGraduação em Comunicação e Cultura da Escola de Comunicação da Universidade Federal do Rio de Janeiro, Rio de Janeiro, 2006.

CASSETA \& PLANETA. A taça do mundo é nossa. Rio de Janeiro: Objetiva, 2003.

FIGUEROA, Alexandre; FECHINE, Yvana. Guel Arraes: um inventor no audiovisual brasileiro. Recife: CEPE, 2008.

FIGUEROA, Alexandre; FECHINE, Yvana. Cinema e televisão no contexto da transmediação. In: RIBEIRO, Ana Paula Goulart; SACRAMENTO, Igor; ROXO, Marco (Org.). História da televisão no Brasil: do início aos dias de hoje. São Paulo: Contexto, 2010. p. 281-311

KORNIS, Mônica Almeida. Uma história do Brasil recente nas minisséries da Rede Globo. 2001. Tese (Doutorado em Artes) - Escola de Comunicações e Artes da Universidade de São Paulo, São Paulo, 2001.

KORNIS, Mônica Almeida. Fiç̧ão televisiva e identidade nacional: o caso da Rede Globo. In: CAPELATO, Maria Helena et al. (Org.). História e cinema: dimensões históricas do audiovisual. São Paulo: Alameda, 2007. p. 97-114

KORNIS, Mônica Almeida. As revelações do melodrama, a Rede Globo e a construção de uma memória do regime militar. Significação, São Paulo, v. 38, n. 36, p. 173-193, 2011.

MACHADO, Arlindo. A televisão levada a sério. São Paulo: Senac, 2000.

MARTINS, Andréa França. 0 pensamento do documentário na televisão brasileira: a década de 1970. Revista Eco-Pós, Rio de Janeiro, v. 14, n. 2, p. 129-141, 2011.

SACRAMENTO, Igor. Nos tempos de Dias Gomes: a trajetória de um intelectual comunista nas tramas comunicacionais. 2012. Tese (Doutorado em Comunicação e Cultura) Programa de Pós-Graduação em Comunicação e Cultura da Escola de Comunicação da Universidade Federal do Rio de Janeiro, Rio de Janeiro, 2012.

SACRAMENTO, Igor. Depois da revolução, a televisão: cineastas de esquerda no jornalismo televisivo dos anos 1970. São Carlos: Pedro \& João Editores, 2011. 


\title{
From television to cinema: parody and memory of the Brazilian military dictatorship
}

\begin{abstract}
This study examines how the films $A$ taça do mundo é nossa (2003), directed by Lula Buarque de Hollanda, and Reis e ratos (2012), directed by Mauro Lima, represent the Brazilian military dictatorship. Within the debate about the context of transmidiation in cinema and television, we intend to discuss how, in both films produced by Globo Filmes, the construction of a memory of that period was made as a parody, based on well succeed models from television created by Rede Globo during the eighties by Guel Arraes and by Casseta \& Planeta group. In the cinema, these models surely lost the innovative dimension that they had at time they were made as television series. Simultaneously, they construct a memory that places that period as something concluded, far from the tensions of the moment when those films were produced.
\end{abstract}

\section{Keywords}

Television. Cinema. Brazilian military dictatorship. Rede Globo. Globo Filmes.

Recebido em 01/10/2015

Aceito em 14/12/2015 